\title{
Understanding the tree of life: an overview of tree-reading skill frameworks
}

\author{
Thilo Schramm* ${ }^{*}$, Yvonne Schachtschneider and Philipp Schmiemann (1)
}

\begin{abstract}
Diagrammatic depictions of evolutionary relationships play an increasingly important role in scientific and educational literature. Reading evolutionary trees is seen as a major challenge for biologists in learning about evolution and its applications in research. The skills needed to read, interpret, and construct evolutionary trees are subsumed under the term "tree-thinking," which can be divided into "tree-reading" and "tree-building."The purpose of this paper is two-fold. First, we review relevant literature on tree-reading skills to examine regularly reported skills for an up-todate overview of the topic and to determine where further investigation might be needed. Second, we compare and contrast published skills and skill systems to highlight commonalities and differences using a published hierarchical system as a framework and integrating the skills identified by other authors by arranging them with their corresponding skills within the framework. The resulting insights suggest a possible synthetic tree-reading model. By bringing together the relevant literature about tree-reading skills, we show that research on tree-thinking skills has until now been conducted mainly following theoretical or observational approaches, often lacking cross-references linking different works; this has resulted in multiple approaches. Furthermore, as most published systems have not been empirically tested, it seems useful to collect existing findings for empirical testing to create a synthetic tree-reading skill model that can be used by educators to structure and organize their learning environments. Teaching the subdomains of tree-reading in order of difficulty can facilitate the entire learning process. Furthermore, the skill model can be used to design testing instruments for education and research that incorporate the full range of tree-reading subdomains and thus, may be better suited to distinguish more advanced learners from less advanced ones.
\end{abstract}

Keywords: Tree-thinking, Tree-reading, Evolutionary tree, Phylogenetic tree

\section{Introduction: why are evolutionary trees important?}

Graphical representations play a major role in modern learning environments. Various types of graphs, diagrams, charts, and schemata can be found in all areas of scientific research and various forms of learning materials (Lee 2010; Purchase 2014; Shah et al. 2005). This applies in particular to biology, where students are regularly confronted with a large variety of different representational styles in its many subdomains (Roth and Pozzer-Ardenghi 2013; Wiley et al. 2017).

Teaching biological fields like microbiology, genetics, and evolution involves teaching abstract processes

${ }^{*}$ Correspondence: Thilo.Schramm@uni-due.de

Biology Education, University of Duisburg-Essen, Universitätsstraße 5, 45141 Essen, Germany that may not be observed by students. Furthermore, the concept of evolution is not intuitive (Gregory 2009). Evolution is the conjunctive core principle of biology (Dobzhansky 1973; Futuyma 2013) and in order to develop a deeper understanding of any biological discipline, one needs to grasp the concepts of evolution (Meisel 2010). Its understanding requires knowledge of various different and seemingly unrelated topics like genetics, ecology, and morphology (Horwitz 2013), and opportunities for practical work are rare (Besterman and La Baggott 2007). This leads to evolution being seen as one of the most challenging topics to teach in introductory science courses (Beardsley et al. 2012; Besterman and La Baggott 2007). The difficulty in teaching evolution is compounded by numerous and very persistent misconceptions prevalent among learners of all ages and education levels (Gregory 2009; Chinsamy and Plagányi 2008; 
Hokayem and BouJaoude 2008; Mead and Scott 2010a, b; Yates and Marek 2014, 2015).

\section{Evolutionary trees as a representation of evolution}

Evolutionary diagrams are diagrammatic depictions of different species or groups and their relatedness. They can exist in different forms (e.g., the ladder of life or the Great Chain of Being), although treelike depictions are the most common (Catley and Novick 2008). Crucial for evolutionary diagrams is that they present the evolutionary development of species and groups rather than the development or relatedness of individual organisms. In this paper, we will treat terms like "evolutionary tree," "phylogenetic tree," and "phylogeny" as interchangeable, although some experts in the field might use them with different connotations.

Evolutionary trees are a very common way to visualize patterns of macroevolutionary processes and therefore play a central role in teaching evolution (Baum et al. 2005; Nehm and Kampourakis 2014). They serve as a tool to depict multiple relationships in one diagram, thus presenting processes and developments that are hard to describe in a simple way (Halverson and Friedrichsen 2013). In order to understand how evolution works, one has to understand how cladogenesis works, which is facilitated by knowing how speciation processes are represented in diagrams (Catley et al. 2012; Meisel 2010).
Evolutionary trees can be used to visualize how certain traits of a living organism evolved in relation to other traits and organisms (see Fig. 1). In the absence of other data (like a rich fossil-record), the most parsimonious explanation is typically used to make claims about the course of the development of certain traits. Following this approach, the most plausible pattern of relationships is the one that requires the lowest number of evolutionary changes (Baum and Offner 2008). Many evolutionary trees show the changes in the characteristics along with the development of groups by labeling the tree with newly developed traits (Baum and Smith 2013). These labeled traits are often subsumed under the term apomorphies, although phylogeneticists further distinguish them with expressions like plesiomorphic, autapomorphic, or homoplasic. By analyzing the occurrence of different traits across different groups, one can infer the pattern of the relationship of these groups.

Besides visualizing and confirming the course of evolution, evolutionary trees can be used in a variety of contexts, such as conservation biology (illegal whale hunting) (Baker and Palumbi 1994), forensics (the ways in which HIV is transmitted) (Ou et al. 1992), agriculture (the effects of pesticides) (Engelen et al. 1998), medicine (the development of the hantavirus) (Yates et al. 2002), drug development (predictive evolution) (Bush et al. 1999), or drug design (Searls 2003). As phylogenies and biological

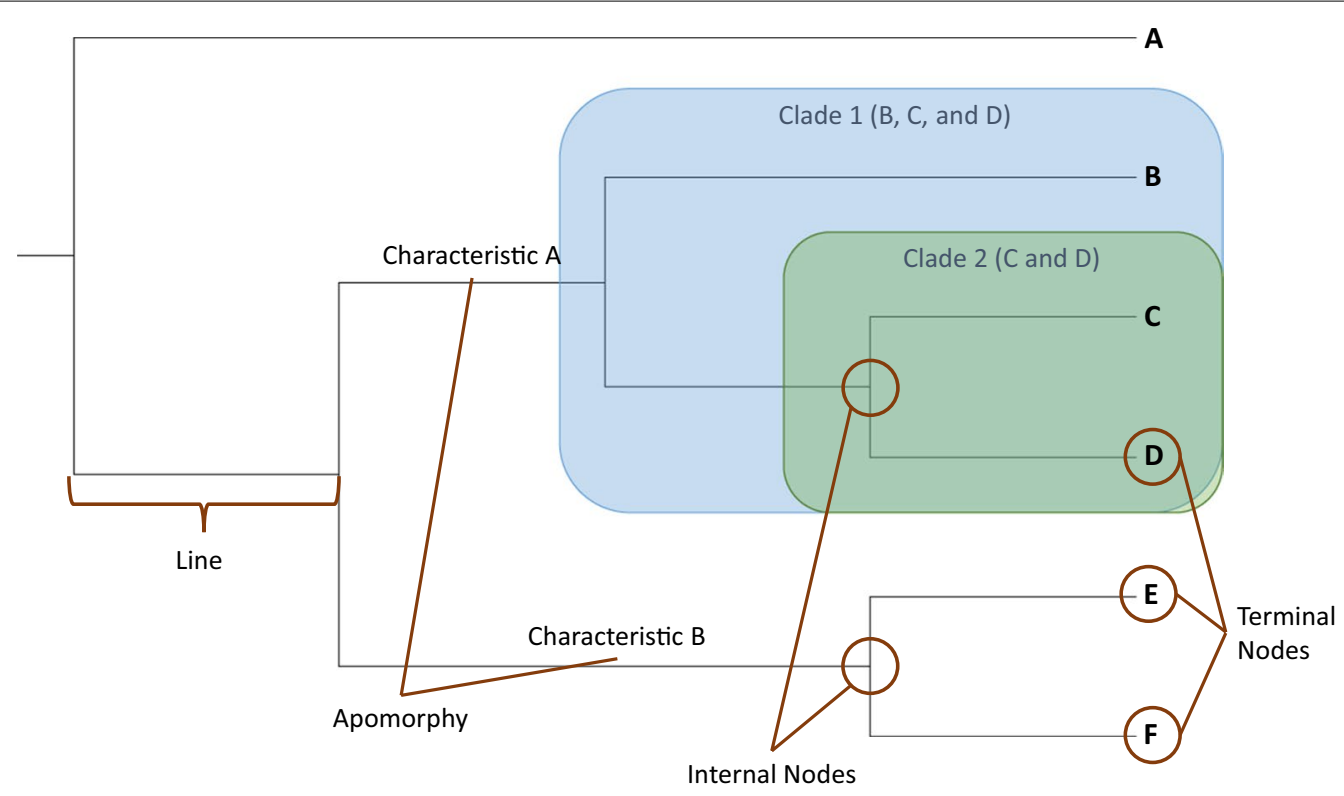

Fig. 1 Properties of an evolutionary tree. An evolutionary tree consists of three basic components: internal nodes, lines, and terminal nodes. Lines are representations of lineages. Points where a lineage bifurcates are marked by internal nodes, representing the most recent common ancestor of all descending groups. Terminal nodes appear at the end of lineages and most regularly represent extant species or groups. Along the lines, apomorphies (evolutionary newly developed traits) can be displayed to emphasize and explain the bifurcation event. A nested hierarchy of clades (a common ancestor and all its descendants) is created by the bifurcations at internal nodes 
classification are an important part of biology, they are part of the school curricula of such countries as the USA, the UK, Australia, and New Zealand (Catley et al. 2013).

\section{Tree-thinking}

When working with evolutionary trees, one has to analyze, interpret, and reason with the information given in the representation. This practice is called tree-thinking (O'Hara 1997). Some authors describe tree-thinking as a mere set of skills needed to extract relationship information from an evolutionary tree (O'Hara 1997), while others describe it as a "habit of mind that uses the history of life on earth as its first line of evidence while providing students with a hierarchical view of the natural world" (Catley and Novick 2008) or as "the ability to visualize evolution in tree form and to use tree diagrams to communicate and analyze evolutionary phenomena" (Baum and Smith 2013). There is no unifying definition of the term tree-thinking, but the various definitions and descriptions tend to resemble each other closely (Blacquiere and Hoese 2016; Catley et al. 2012; Gibson and Hoefnagels 2015; Halverson et al. 2011). The common idea across the different definitions is that tree-thinking is needed in order to be able to extract information about relationships from an evolutionary tree, to make conclusions and inferences about the displayed course of evolution, and to construct evolutionary trees from the given data. Treethinking is seen as a prerequisite to studying and understanding macroevolution (Catley et al. 2012).

As the definitions cited above indicate, tree-thinking is not restricted to the mere acts of reading and building evolutionary trees, but also to using tree-diagrams as a tool for communication and new insights. In science, different trees and branching patterns are contrasted with each other to investigate hypotheses. These acts of analyzing phylogenies might be counterintuitive to novices in biology, as they often base their interpretation of evolutionary relationship only on single characters (e.g., a specific morphological trait, or a certain behavior) instead of considering all given information, especially the branching pattern (Gregory 2008; Halverson et al. 2011). Relying on a single trait or a small number of characteristics is not seen as suitable to get a reliable estimate on the relative relationship of species (Gendron 2000). Different studies have shown that students struggle with understanding evolutionary trees and display a great variety of widespread learners' misconceptions (Baum et al. 2005; Gregory 2008; Kummer et al. 2016; Meir et al. 2007; Omland et al. 2008; Thanukos 2009).

According to Halverson (2011), tree-thinking can be separated into two parts: tree-reading and tree-building. The former encompasses all activities of interpreting, analyzing, and reasoning with a given tree. The latter incorporates all tasks that lead to the construction of a new tree, ranging from the general concept of how to construct a tree from given data to the broad field of phylogenetic inference. Halverson (2011) was able to show that tree-reading serves as a prerequisite to tree-building. As most of the theoretical work on tree-thinking focuses on tree-reading, this paper concentrates on this aspect as well.

\section{Tree-thinking skills}

Although several authors have worked on general treethinking in recent years (see Table 1), only little research has dealt with the skills constituting tree-thinking. In this section, we review published skills and skill systems describing tree-reading. We start by presenting skills published by different authors that are not embedded in a skill system. Next, we present a non-hierarchical treereading skill system developed by Novick and Catley

Table 1 Overview of works on tree-reading skills

\begin{tabular}{|c|c|c|c|c|}
\hline Authors & Year & Published tree-reading skills & Sample size & Context \\
\hline Blacquiere and Hoese & 2016 & One most fundamental skill for tree-reading & 205 College students & $\begin{array}{l}\text { Developing an instrument to assess students' } \\
\text { abilities in determining evolutionary } \\
\text { relationships }\end{array}$ \\
\hline Halverson & 2011 & 3 non-systematized skills & 27 college students & $\begin{array}{l}\text { Assessing how students interpret and build } \\
\text { evolutionary trees and which core skills are } \\
\text { essential for tree-thinking }\end{array}$ \\
\hline Halverson and Friedrichsen & 2013 & $\begin{array}{l}\text { Tree-thinking skill hierarchy with seven } \\
\text { levels }\end{array}$ & 157 college students & $\begin{array}{l}\text { Developing a hierarchical framework for tree- } \\
\text { thinking skills }\end{array}$ \\
\hline Meir et al. & 2007 & 3 non-systematized skills & 410 college students & Study of misconceptions in tree-thinking \\
\hline Novick and Catley & 2013 & Non-hierarchical system of 5 skills & 107 college students & $\begin{array}{l}\text { Studying factors that can influence students' } \\
\text { competence in tree-thinking }\end{array}$ \\
\hline Novick and Catley & 2016 & Non-hierarchical system of 11 skills & 135 college students & $\begin{array}{l}\text { Comparing two approaches of teaching } \\
\text { tree-thinking }\end{array}$ \\
\hline
\end{tabular}


(2013), followed by a hierarchical tree-thinking skill system developed by Halverson and Friedrichsen (2013).

\section{Non-systematized tree-thinking skills}

Meir et al. (2007) were the first to propose explicit treethinking skills. They developed an instrument to gauge misconceptions of college students involved in treethinking that consists of multiple choice and open-ended questions (including tasks of constructing tree diagrams). The instrument was given to a total of 410 students from different colleges in the US who had completed at least one course in evolutionary biology. While the main findings of this study were the identification of four major and widespread misconceptions, the authors also took a closer look at three skills they saw as important in treethinking: (A) "Reading traits from trees" describes the ability to deduce which characteristics a certain species shows given a tree with labelled apomorphies. (B) "Deducing ancestral traits" is the ability to infer which characteristics the MRCA of a given set of species most likely showed. The final skill, (C) "reconstructing trees," relates to building an evolutionary tree from a given set of species and their traits (Meir et al. 2007). Relative shares of students showing faulty understanding of each of the three skills ranged from 65 to $84 \%$ per skill. Students in upper classes only showed better results concerning skill (A) "Reading traits from trees"; for the other skills, no statistical differences could be found. The authors claim that such lacks in skills and persistent misconceptions throughout secondary and post-secondary education might pose substantial hurdles for a deeper understanding of evolution and for connecting different fields of biology through evolution (Meir et al. 2007).

A different approach was chosen by Halverson (2011), who analyzed multiple open-ended sources from 27 undergraduate students of an upper-level plant systematics course at a US university, finding three distinct tree-reading skills. The analyzed sources included weekly online reflective journals, pre-posttests, students' responses to homework and exam questions, and notes about the process of the course and interviews with 13 of the total 27 students. The analysis of these data sources followed two main questions: How do students interpret, compare, and build evolutionary trees, and what core skills are essential for representational competence in tree-thinking? In the light of this review, the second question in particular was found to be of major importance. Halverson found trends in the changes of the rationales given by the students over the course of the semester that could be summarized as three skills of tree-reading: "Recognition and Understanding," "Identification and Use," and "Evidentiary Support" (Halverson 2011). "Recognition and understanding" describes the knowledge of the meaning of key features of an evolutionary tree, like branches, nodes, and the direction of time flow. "Identification and use" describes the use of scientific approaches for reading and interpreting evolutionary trees, like understanding and using the concept of clades, the most recent common ancestor, and the concept of rotating branches around nodes. "Evidentiary support" describes the ability to use information from evolutionary trees to support claims as evidence for inferences and to make predictions about phylogenies. In this work, earlier works on tree-reading skills are not explicitly mentioned or referred to.

Focusing on one particular skill in their study assessing college students' skills in reading evolutionary relatedness from phylogenetic trees, Blacquiere and Hoese (2016) claim that one of the most fundamental skills in tree-thinking is knowing about the concept of the MRCA. Deciding which two species share a more recent common ancestor than the others is a key aspect in evaluating evolutionary relationships (Blacquiere and Hoese 2016). The study focused on establishing a valid assessment tool with an emphasis on the stated skill. The developed instrument was tested on 205 US college students and was able to identify students distracted by alternative strategies for determining relationships from evolutionary trees.

\section{Non-hierarchical tree-reading framework}

A non-hierarchical system of tree-reading skills has been proposed by Novick and Catley in two development steps. The first published system consists of five skills, with several sub-skills focusing mainly on the varying relative positioning of the examined clades (Novick and Catley 2013). Skill 1 is the identification of a trait shared by taxa due to inheritance from their most recent common ancestor (MRCA). Skill 2 regards identifying a group of species that share a certain trait. Skill 3 describes the comprehension of the concept of clades. This skill is subdivided into two skills in relation to identifying processes: first, deciding whether or not a group of taxa form a clade, and second, identifying a subset of taxa that form a clade. Skill 4 is the ability to conclude evolutionary relatedness. The last skill, Skill 5 , pertains to making inferences about relationships not depicted in the tree (Novick and Catley 2013). No claim of a hierarchy of skills is made by the authors. The focus of the study was on assessing the extent to which these five skills are affected by conceptual factors, like biology background, prior knowledge, and question wording, as well as perceptual factors in the construction of the presented trees. In this work, the authors mention previous works in the field on tree-reading skills, but do not explicitly cross-reference their findings. 
In a later work, the same authors revised and expanded their skill system (Novick and Catley 2016). This new set consists of 11 skills, of which 7 were part of the first skillset, either as main skills or as subskills. In this new set, the skills are not numbered, and no hierarchy is proposed by the authors. To avoid confusion, we labeled these skills A through $\mathrm{K}$, but this should not be taken as implying a hierarchy. The skills are presented below in the order in which they appear in the authors' publication (Novick and Catley 2016).

The first skill, (A) "identify characters," covers identifying which characters specific species or groups share because of their descent from an MRCA. (B) "Identify taxa" is a skill closely related to (A), as it describes the reverse relation. Here students name taxa that share certain characters. Both skills rely on apomorphies being labeled in a given evolutionary tree. Skill (C) "identify/ evaluate clades" encompasses the ability to group species according to their ancestry into monophyletic clades. (D) "Identify nested clades" is the fourth skill, which involves ascertaining different hierarchical levels of nested clades in a given tree.

The fifth and sixth skills, (E) "evolutionary relationship: resolved structure" and (F) "evolutionary relationship: polytomy," both pertain to evaluating the relative relatedness of a group of taxa, but with different levels of complexity in terms of the branching pattern. (G) "Inference," the seventh skill, describes the ability to make inferences about phylogenetic relationships based on the depicted information. Skill $(\mathrm{H})$, "evolutionary sequence," is described as identifying the order of appearance of traits on a given evolutionary path. (I) "Convergent evolution" is the ability to identify convergent evolution in a given cladogram. The two last skills, (J) "subsets of the tree of life" and (K) "rotation," regard coping with manipulations of a given tree, the former with different subsets of a given tree and the latter with rotations in a tree.

Novick and Catley (2016) assessed these tree-thinking skills by creating an instrument of 37 multiple choice and open-ended questions, each one clearly linked to one of the stated skills. The instrument was administered to 135 students of a second-semester introductory biology course for science majors at an American university. In their pre-post study, they compared two different teaching methods of phylogenetics whose skills were used to subdivide the students' performance for a more detailed view of individual learning progressions. There are no reports of an in-depth analysis of the validity of the skill model. The authors refer to their previous work on modelling tree thinking skills, as well as on singular works, to substantiate the presented skills.

The genesis of these two sets of skills is based on the longtime teaching and research experience of the authors in the field of evolutionary trees (Novick and Catley 2013) and is backed up by literature reference. These skills can be used to select content for a tree-reading teaching unit, but in the absence of a hierarchy of the skills, no recommendation is offered regarding the order in which the different skills should be taught. So far, the skill system has not been tested to determine whether the different skills can be empirically differentiated.

\section{A hierarchical framework for tree-thinking}

Halverson and Friedrichsen (2013) developed a hierarchical framework for tree-thinking skills. The hierarchy is based on the work of Kozma and Russell (2007) in the field of chemistry education and presents a skill set for the use of visual representations.

Using this system as a basis, Halverson and Friedrichsen (2013) collected data from upper-level students in their evolutionary systematics courses. They collected data from 157 students of two US universities over the course of 4 years. The data sources include students' online reflective journals, pre-posttests, and semi-structured interviews, as well as written coursework from students and notes from course observations.

By combining these data with Kozma and Russel's model (Kozma and Russell 2007) and Halverson's previous work (Halverson 2011), Halverson and Friedrichsen (2013) presented a seven-level hierarchical tree-reading and tree-building skill model called the "Representational Competence Framework for Tree Thinking." The seven skill levels are described below.

(1) At the first level ("no use of representation"), students do not use the information depicted in the representation; instead, they tend to use prior knowledge about the morphology and ecology of the presented organisms. (2) At the second skill level ("superficial use of representation"), the students' interpretation is based upon superficial features of the given tree, not responding to the underlying meaning of the representation. (3) Students at the third level ("simplified use of representation") base their interpretation of the tree on the concept of a main branch from which the other taxa branch off, while comparisons of different trees are based on differences in branch length (Halverson and Friedrichsen 2013).

(4) Students at the fourth skill level ("symbolic use of representation") use the correct symbolic meanings of the elements of the tree but overemphasize the meanings of nodes. (5) On the fifth level ("conceptual use of representation"), students view the two-dimensional representation as an effigy of a three-dimensional representation, thus understanding the possibility of branches rotating around nodes without altering the kinship of the species. Comparisons between different 
trees are restricted to the mere physical branching patterns while students consider the possibility of rotating branches of the tree. (6) Students at the sixth level ("scientific use of representation") are able to interpret the depicted relationships in a scientifically correct way based on common ancestry, monophyletic patterns, and implied apomorphies separating taxa. The style of the representation does not play a role in the interpretation as the pattern of the clades is evaluated (Halverson and Friedrichsen 2013).

(7) The seventh level ("expert use of representation") is typically not achieved by students, as it represents the skill level of experts in the field of systematics. These experts are able to quickly understand and interpret the phylogenetic structure of the representation and can use and modify multiple representations in order to solve problems and make inferences about relationships and evolutionary processes. They can reason regarding whether different representational styles are better suited a given task (Halverson and Friedrichsen 2013).

To summarize, the first three skill levels show an incomplete grasp of tree-thinking on different levels characterized by different misconceptions, while the fourth skill represents the basic grasp of diagrammatic features and representational norms that are the basis for actual tree-thinking processes. Level four is the first level showing scientifically correct interpretations and analysis, although students still show grave misconceptions and therefore arrive at faulty conclusions. Skill levels five and six represent general tree-thinking abilities, covering major tasks like handling rotations and identifying evolutionary relationships. Halverson and Friedrichsen state that the last skill level is exclusive to long-time experts in the field of tree-thinking and therefore is not likely to be achieved by any student during their academic studies (Halverson 2011; Halverson and Friedrichsen 2013).

Halverson and Friedrichsen evaluated their students' representational capability using the Representational Competence Framework for Tree Thinking. They analyzed selected answers in tests and rationales in open data formats. The skill system can be used to describe learners from absolute novices up to experts with multiple years of experience in the field. Depending on the task at hand, a learner can be matched to different skill levels at one point of time, for example showing level one when interpreting relationships presented in a single tree but level three when comparing patterns of relationships among multiple trees (Halverson and Friedrichsen 2013). The hierarchical nature of the skill system has so far not been empirically tested. The authors refer to Halverson's previous works on tree-reading skills, but explicitly to no other authors.

\section{Similarities and differences in tree-reading skill frameworks}

In the following section, we will compare and contrast the different published skills and skill systems in order to obtain a more detailed view of the extent of the published findings. As a scaffold, we use the hierarchy of Halverson and Friedrichsen (2013). Published skills are compared with respect to their content and the described tasks and requirements; corresponding skills were then arranged next to each other (see Table 2). The insights of this arrangement should serve as a basis for proposing an idea of a possible synthetic hierarchical tree-reading skill model in the next section.

A detailed comparison of the two skill systems (see Table 1) shows that Novick and Catley's skill system only corresponds to three of Halverson and Friedrichsen's skill levels, namely skill level (5) "conceptual use of representation" (skills J and K), skill level (6) "scientific use of representation" (skills A, B, C, D, E, F, H, and I), and skill level (7) "expert use of representation" (skill G). There are no skills in Novick and Catley's system corresponding to Halverson and Friedrichsen's skills (1), (2), (3), and (4).

Meir et al's (2007) skill (A) "reading traits from trees" fits Halverson and Friedrichsen's skill level 6 and the corresponding skills of Novick and Catley. Meir and colleagues' skill (B) "deducing ancestral traits" corresponds to Halverson and Friedrichsen's skill level (7) "expert use of representation," as a deep understanding of evolutionary processes is required. Skill (C) "reconstructing trees" is omitted in this work, as it deals with building evolutionary trees. Blacquiere and Hoese's (2016) statement that knowledge of MRCA is the most important for treethinking is represented in this comparison by Halverson and Friedrichsen's level (6) ("scientific use of representation"), and is the basis for two of Novick and Catley's skills ( $E$ and $F$ ) for assessing the relative evolutionary relatedness of three taxa.

\section{Conclusion: synthesizing tree-reading frameworks}

Our review shows that there are some well-elaborated works on tree-reading skills that thus far have not explicitly referred to each other. The two major systems show different approaches: Halverson and Friedrichsen (2013) consider the total spectrum of learners' progress in handling evolutionary trees, from absolute novices to longtime experts, in a hierarchical structure. Novick and Catley (2016) use a smaller-scale approach, describing task-oriented skills needed for fully understanding treereading. Novick and Catley's task-oriented system seems suitable for easily generating learning assignments, while Halverson and Friedrichsen's system seems to constitute a good basis for structuring a complete process of 
Schramm et al. Evo Edu Outreach $\quad$ (2019) 12:11

Page 7 of 13

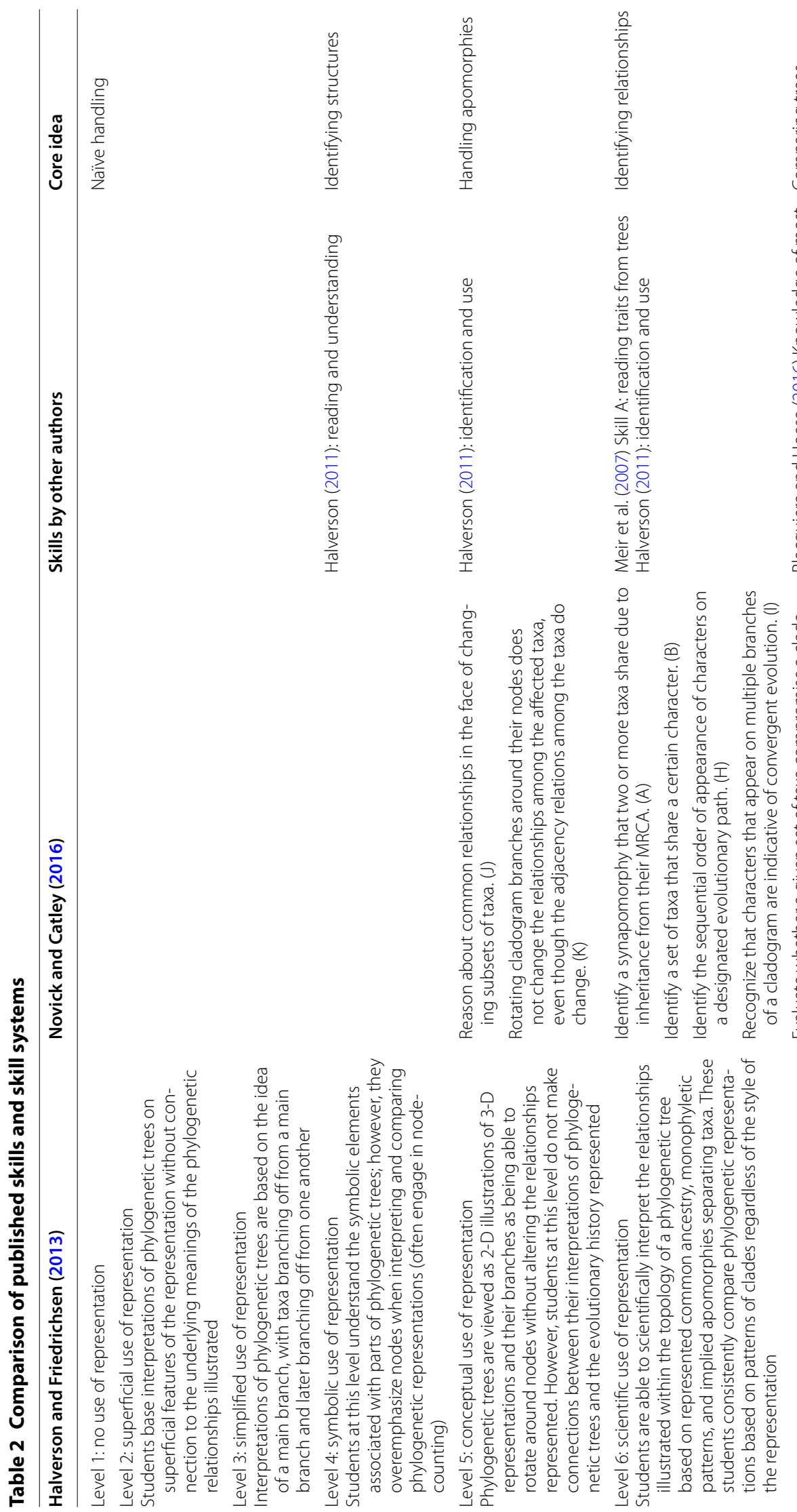




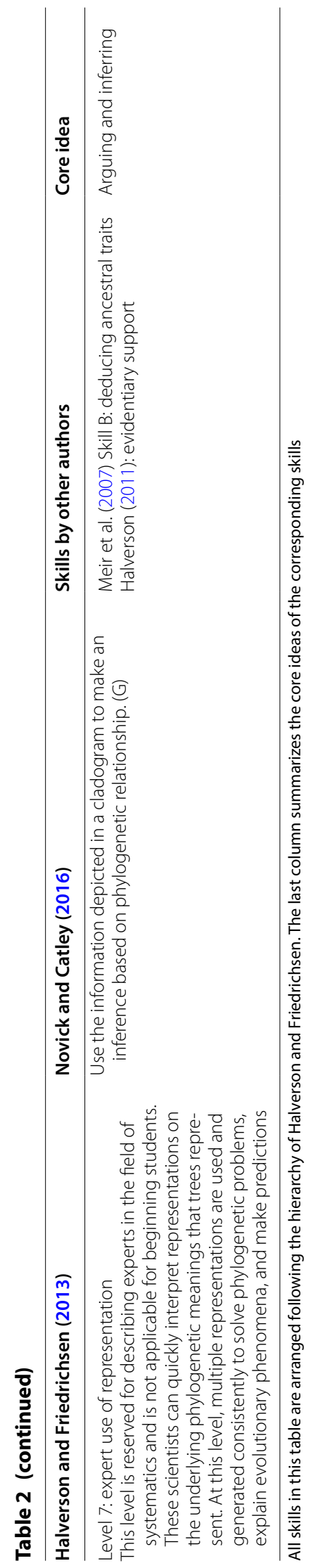


learning by starting to dismantle common misconceptions and then improving skills with increasing difficulty in ordered sequence. The skills proposed by other authors substantiate several skills or skill levels in the skill systems.

In general, our literature overview shows that multiple groups have worked on modeling tree-reading skills, and some major advancements have been made. At the same time, however, it has become clear that there has been no attempt to unify and combine the insights already gained. Publications show only few cross-references to works on tree-reading skills by other authors, leading to mainly singular, not explicitly interlinked approaches. Furthermore, research on tree-thinking skills so far has focused on deducing skills or systems from theory, observation, or experience, and there has been no major attempt to empirically verify the proclaimed models.

Based on the works published on tree-thinking skills (Halverson and Friedrichsen 2013; Novick and Catley 2016) and on skills published by other authors (Blacquiere and Hoese 2016; Meir et al. 2007), we wish to present a proposal for a synthetic hierarchical system of tree-reading skills consisting of six skill levels. This system could at this point be seen as an example of how such a synthesis might look, as it is the result of a theoretical approach drawing together the previous works of different authors.

The hierarchical nature of this system largely follows the hierarchy of Halverson and Friedrichsen's system (2013), although one minor adjustment of the order has been made, as explained below. The structure of the proposed system, along with the allocation of the proposed skill levels to published skill systems, is also explained below, as well as presented in Table 1 in the form of major ideas.

The hierarchy starts at skill level zero ("naïve handling"). Students at this level are not able to analyze a tree correctly, nor do they know the symbolic meaning of the different components of the tree. Interpretations of a given tree are largely based on one or more learners' misconceptions and tend to over-interpret uninformative facets of a tree diagram over others. This level corresponds to the first three skills of Halverson and Friedrichsen, which are all characterized by fragmented knowledge of evolutionary trees (Halverson and Friedrichsen 2013).

Skill level one ("identifying structures") represents the ability to identify and interpret the meaning of diagrammatic elements of the representation. This includes knowledge of the meaning of nodes, branches, labels, and the direction of time, but also slightly more elaborate knowledge, like the positions of MRCAs in the tree. This level corresponds with Halverson and Friedrichsen's level four ("symbolic use of the representation"), where the students have knowledge of the meaning and importance of diagrammatic features but cannot interpret the diagram any further (Halverson and Friedrichsen 2013).

The second skill level ("handling apomorphies") encompasses the ability to interpret traits labeled in a tree. This includes tasks in both directions, naming all traits that a taxon shows and listing all taxa that show certain traits. This skill can only be utilized if the given tree shows traits or apomorphies by any representational means (e.g., pictorial or textual, along the lines, with reference markings, etc.). The basis for this skill level is the combination of several skills proposed by Novick and Catley (2016), all of which focus on identifying and interpreting labelled apomorphies [(A) "identify characters," (B) "identify taxa," (H) "evolutionary sequence," and (I) "convergent evolution"]. In Halverson and Friedrichsen's model, handling apomorphies is part of the extensive skill level (6). It was separated into a distinct skill level, as many evolutionary trees do not show apomorphies, so handling apomorphies is not a skill generally needed to understand every tree, but it can greatly improve the handling of a tree if apomorphies are present (Catley et al. 2010; Novick et al. 2010).

The third skill level ("identifying relationships") describes the core tasks of tree-reading. This skill covers all tasks that answer questions about the relative relationships of different species and the formation of clades in a given tree. Typical questions at this level are "Which group is the closest relative to group $\mathrm{X}$ ?", "Is group $\mathrm{X}$ more closely related to group $Y$ than to group $Z$ ?", and "Which groups form a clade with groups X, Y, and Z?" This level corresponds to four of the skills of Novick and Catley (2016) [(C) "identify/evaluate clades," (D) "identify nested clades," (E) "evolutionary relationship: resolved structure," and (F) "evolutionary relationship: polytomy"] and to skill level six of Halverson and Friedrichsen. It consists of a set of skills pertaining to evaluating monophyletic groups and relative evolutionary relationships.

The fourth skill level ("comparing trees") incorporates the ability to mentally rotate branches in a tree, to analyze subtrees, and to decide whether given trees show the same or different relationships. The same applies to comparing different representational styles (e.g., rectangular, circular, and diagonal trees). This level corresponds to two skills identified by Novick and Catley [(K) "rotation" and (J) "subset of the ToL"] and to Halverson and Friedrichsen's skill level five ("conceptual use of representation"). At this point, we diverged from Halverson and Friedrichsen's skill hierarchy, as this skill does not refer merely to the knowledge that trees can be rotated around nodes, but to the more complex task of reasoning about relationships with different subsets and the 
appearance of a tree. Furthermore, analyzing and comparing multiple evolutionary trees requires the formation of multiple complex mental models (Hochpöchler et al. 2013). Comparing two trees requires the learner to process many more graphical elements at the same time than when evaluating the relative relationships of a number of species (Kim et al. 2000). Thus, this skill necessitates the ability to evaluate evolutionary relationships in a very complex and demanding way and has to follow skill level four. The understanding that trees can come in different formats but are informationally equivalent can be found in skill level six of Halverson and Friedrichsen's system. This is also an aspect of our fourth skill level. Therefore, we deviated from the hierarchy of Halverson and Friedrichsen in this respect.

The fifth and final level ("arguing and inferring") aims at going beyond the given information in the representation. It covers the ability to form conclusions and predictions based on the phylogeny, which may extend to taxa or traits not presented. It is based on Halverson and Friedrichsen's level seven ("expert use of representation") and represents the ability to interpret evolutionary trees in a deeper way than students are normally able to. Depicted information is used to form inferences and arguments that go beyond the presented information. This includes forming new mental models of composite trees, solving complex phylogenetic problems, and deciding which tree formats are best suited to different means of representation. The resulting skill levels, together with an explanation of the levels and the corresponding skills by other authors, can be seen in Table 3 .

\section{Discussion, implications, and limitations}

As tree-thinking is seen as an increasingly important part of biological literacy (Baum and Smith 2013; Thanukos 2009) it is important to note that students at all educational levels struggle in engaging with evolutionary trees (Catley et al. 2012; Gregory 2008; Kummer et al. 2016;
Omland et al. 2008). Different authors have called for the implementation of tree-thinking in school curricula in order to improve students' knowledge of macroevolution (e.g., Baum et al. 2005; Catley 2006; Meir et al. 2007; Sandvik 2008). To implement tree-thinking in school and university curricula, it is necessary to further outline the concept and concretize its extent.

Utilizing a synthetic model of tree-reading skills like the one proposed here, educators can organize their educational approach to allow students a steady increase in their evolutionary and tree-reading proficiency.

A learning arrangement based on our model might begin with the general importance of evolutionary trees for all of biology, followed by the meaning and importance of diagrammatic elements. To familiarize students with the basic ideas of evolutionary trees, the introduction to tree-thinking can be done using circle-in-circle diagrams to represent the nested hierarchical nature of evolutionary trees (Catley et al. 2005; Meisel 2010), or by using family pedigrees so students can draw on their intuitive evaluation of relative relationship. By reducing a pedigree to a maternal line-for example, one outlining mitochondrial heredity-the structure of evolutionary trees can be learned intuitively (Baum et al. 2005). By zooming out from this pedigree over a tree to show the relationship within a population to trees showing different species, the connection to evolutionary trees can be established (Baum and Offner 2008; Meisel 2010).

Reading and interpreting apomorphies on a given tree could be the next step in the learning arrangement, followed by teaching the interpretation and specifying relationships. A potential way to familiarize students with apomorphies is the card-laying task "Great Clade-Race," in which students construct a tree based on trait combinations by retracing a metaphorical evolutionary process (Goldsmith 2003). A further opportunity to foster a deeper understanding of apomorphies are hands-on activities where students craft organisms from different

Table 3 Possible example of a synthetic, hierarchical tree-reading skill model

\begin{tabular}{|c|c|}
\hline Skill level & Skill description \\
\hline 0. Naïve handling & $\begin{array}{l}\text { Students do not interpret the tree correctly. Uninformative features are over-interpreted and critical misconceptions are } \\
\text { applied }\end{array}$ \\
\hline 1. Identifying structures & $\begin{array}{l}\text { Students are able to identify and interpret the elements of the diagram (nodes, branches, labels, direction of time, etc.) and } \\
\text { can answer questions about the structure of the tree }\end{array}$ \\
\hline 2. Handling apomorphies & $\begin{array}{l}\text { Students are able to answer questions about the meaning and implications of apomorphies. Taxa can be grouped accord- } \\
\text { ing to occurring apomorphies }\end{array}$ \\
\hline 3. Identifying relationships & $\begin{array}{l}\text { Students are able to state whether groups form clades and can evaluate the relative relatedness of a set of taxa. This } \\
\text { includes simple and complex statements about the relationship of three taxa and about taxa and their MRCA }\end{array}$ \\
\hline 4. Comparing trees & Students are able to reason about relationships when different trees (like rotations or subtrees) are presented \\
\hline 5. Arguing and inferring & $\begin{array}{l}\text { Students are able to use the depicted information in order to form conclusions and predictions that go beyond the pre- } \\
\text { sented information }\end{array}$ \\
\hline
\end{tabular}


materials and try to recapitulate the occurrence of new traits and species (Brown 2016).

Teaching the evaluation of relative evolutionary relationships presented in a tree can be seen as the heart of tree-reading. Here, educators should stress the importance of examining the most recent common ancestor as the central way to begin evaluating evolutionary relatedness (Blacquiere and Hoese 2016). Numerous known misconceptions may play a crucial role here and should be taken into account by educators (Gregory 2008; Meir et al. 2007). For example, cognitive conflicts and thus a conceptual change could be induced by providing students with typical situations that lead to mistakes that illustrate how and why this particular way of reading a tree is problematic (cf. Vosniadou et al. 2001).

Comparing multiple evolutionary trees could be the next step in the learning arrangement, followed by reasoning tasks going beyond the given tree. As many students struggle with the concept that branches can be rotated around internal nodes, educators must ensure that students internalize this concept. One way to do so is to use modifiable three-dimensional representations, like trees constructed in the form of mobiles (Baum and Offner 2008) or made up of flexible material like pipe cleaners (Halverson 2010). In both models, nodes can be rotated to show that the relative relationship is not altered.

Teaching tree-thinking skills in the order of difficulty might ease the learning process as the learner traverses a steady learning path, starting with easier, more basal concepts and tasks. As learners get deeper insights into tree-reading, the complexity of the concepts and tasks increases.

Besides teaching tree-reading, a synthetic system can also be used to investigate students' skills in a diagnostic or research context. To evaluate students' skills, the full range of skills comprising tree-reading should be evaluated and the difficulty of the diverse skills and skill levels taken into consideration. By using a skill model, researchers can design diagnostic instruments to measure many aspects of tree-reading abilities in consideration of the hierarchical nature of the skill levels and, in this way, get a more detailed view of students' abilities. To facilitate this function of a synthetic system, diagnostic items need to be created that allow for an explicit assessment of different skill levels.

Current research on tree-reading skills mainly focuses on theoretical approaches. The skills published thus far have been deduced from theory, observation, or practice, and the findings of different groups are rarely explicitly crossreferenced in order to combine their insights and give a broader view of the topic. In order to advance the research in this area and enable the actual use of the proclaimed systems and skills, a synthesis of the findings up to the present has to be developed and tested thoroughly to determine whether the skill modeling can be validated empirically.

The proposed example of a synthetic skill system is based on published but not empirically tested skill systems by other authors. Therefore, empirical testing is needed to verify and corroborate the presented system in two ways: one, whether the skill levels follow the proposed hierarchy in difficulty or complexity, and two, whether the different levels can be empirically differentiated. This requires testing students regarding their tree-thinking proficiency using items corresponding to the different skill levels. Although the main foundation for the construction of the proposed skill system is the work of only two groups, one must bear in mind that this is the entirety of the literature currently published on tree-thinking skills.

Furthermore, experimental studies of teaching and longitudinal learning developments are needed to validate a synthetic model. Based on this testing, learning environments and materials can be created to implement a synthetic model in teaching practice.

\section{Authors' contributions}

TS, YS, and PS devised the project, the main conceptual ideas, and the proof outline. TS devised the model and wrote the manuscript with support from YS and PS. PS supervised the project. All authors read and approved the final manuscript.

\section{Acknowledgements \\ We are very grateful to the team of Editage for language review.}

\section{Competing interests}

The authors declare that they have no competing interests.

\section{Availability of data and materials}

The datasets supporting the conclusions of this article are included within the article.

\section{Funding \\ This project is funded by the Federal Ministry of Education and Research under grant number 01PL16075. \\ Additional funding was provided by the Interdisciplinary Centre for Educational Research (IZfB) of the University Duisburg-Essen for professional language editing services and by the Open Access Publication Fund of the University of Duisburg-Essen for publication fees. \\ The responsibilities for the content of this publication lie with the authors.}

\section{Publisher's Note}

Springer Nature remains neutral with regard to jurisdictional claims in published maps and institutional affiliations.

Received: 12 October 2018 Accepted: 30 March 2019

Published online: 12 April 2019 


\section{References}

Baker CS, Palumbi SR. Which whales are hunted? A molecular genetic approach to monitoring whaling. Science. 1994;265(5178):1538-9. https ://doi.org/10.1126/science.265.5178.1538.

Baum DA, Offner S. Phylogenics and tree-thinking. Am Biol Teach. 2008;70(4):222-9. https://doi.org/10.1662/0002-7685(2008)70[222:PT]2. $0 . \mathrm{CO} ; 2$.

Baum DA, Smith SD. Tree thinking: an introduction to phylogenetic biology Greenwood Village: Roberts; 2013

Baum DA, Smith SD, Donovan SSS. Evolution. The tree-thinking challenge. Science. 2005;310(5750):979-80. https://doi.org/10.1126/science.1117727.

Beardsley P, Bloom M, Wise S. Challenges and Opportunities for Teaching and Designing Effective K-12 Evolution Curricula. In: Rosengren KS, Brem SK, Evans EM, editors. Evolution challenges: integrating research and practice in teaching and learning about evolution. Oxford: Oxford University Press USA; 2012. p. 287-310.

Besterman H, La Baggott Velle L. Using human evolution to teach evolutionary theory. J Biol Educ. 2007;41(2):76-81. https://doi.org/10.1080/00219 266.2007.9656066.

Blacquiere LD, Hoese WJ. A valid assessment of students' skill in determining relationships on evolutionary trees. Evol Educ Outreach. 2016;9(1):979. https://doi.org/10.1186/s12052-016-0056-9.

Brown CG. Modeling macroevolution with invented creatures. Am Biol Teach. 2016;78(2):141-8. https://doi.org/10.1525/abt.2016.78.2.141.

Bush RM, Bender CA, Subbarao K, Cox NJ, Fitch WM. Predicting the evolution of human influenza A. Science. 1999;286(5446):1921-5.

Catley KM. Darwin's missing link-a novel paradigm for evolution education. Sci Educ. 2006;90(5):767-83. https://doi.org/10.1002/sce.20152.

Catley KM, Lehrer R, Reiser B. Tracing a prospective learning progression for developing understanding of evolution. Washington, DC; 2005.

Catley KM, Novick LR. Seeing the wood for the trees: an analysis of evolutionary diagrams in biology textbooks. Bioscience. 2008;58(10):976. https:// doi.org/10.1641/b581011.

Catley KM, Novick LR, Shade CK. Interpreting evolutionary diagrams: when topology and process conflict. J Res Sci Teach. 2010;47(7):861-82. https:// doi.org/10.1002/tea.20384.

Catley KM, Novick LR, Funk D. The promise and challenges of introducing tree thinking into evolution education. In: Rosengren KS, Brem SK, Evans EM, editors. Evolution challenges: integrating research and practice in teaching and learning about evolution. Oxford: Oxford University Press USA 2012. p. 93-101

Catley KM, Phillips BC, Novick LR. Snakes and eels and dogs!: Oh, My! Evaluating High school students' tree-thinking skills: an entry point to understanding evolution. Res Sci Educ. 2013;43(6):2327-48. https://doi. org/10.1007/s11165-013-9359-9.

Chinsamy A, Plagányi E. Accepting evolution. Evolution. 2008;62(1):248-54. https://doi.org/10.1111/j.1558-5646.2007.00276.x.

Dobzhansky T. Nothing in biology makes sense except in the light of evolution. Am Biol Teach. 1973:35(3):125-9.

Engelen B, Meinken K, von Wintzingerode F, Heuer H, Malkomes HP, Backhaus H. Monitoring impact of a pesticide treatment on bacterial soil communities by metabolic and genetic fingerprinting in addition to conventional testing procedures. Appl Environ Microb. 1998:64(8):2814-21.

Futuyma DJ. Evolution. 3rd ed. Sunderland: Sinauer Associates; 2013.

Gendron RP. The classification \& evolution of caminalcules. Am Biol Teach. 2000;62(8):570-6. https://doi.org/10.2307/4450980.

Gibson JP, Hoefnagels MH. Correlations between tree thinking and acceptance of evolution in introductory biology students. Evol Educ Outreach. 2015;8(1):1891. https://doi.org/10.1186/s12052-015-0042-7.

Goldsmith DW. The great clade race. Am Biol Teach. 2003;65(9):679-82. https:// doi.org/10.1662/0002-7685(2003)065[0679:TGCR]2.0.CO;2.

Gregory TR. Understanding evolutionary trees. Evol Educ Outreach. 2008;1(2):121-37. https://doi.org/10.1007/s12052-008-0035-x.

Gregory TR. Understanding natural selection: essential concepts and common misconceptions. Evol Educ Outreach. 2009;2(2):156-75. https://doi. org/10.1007/s12052-009-0128-1.

Halverson KL. Using pipe cleaners to bring the tree of life to life. Am Biol Teach. 2010;72(4):223-4. https://doi.org/10.1525/abt.2010.72.4.4.

Halverson KL. Improving tree-thinking one learnable skill at a time. Evol Educ Outreach. 2011;4(1):95-106. https://doi.org/10.1007/s12052-010-0307-0.
Halverson KL, Friedrichsen P. Learning tree thinking: developing a new framework of representational competence. In: Treagust DF, Tsui C-Y, editors. Multiple representations in biological education. Dordrecht: Springer; 2013. p. 185-201

Halverson KL, Pires CJ, Abell SK. Exploring the complexity of tree thinking expertise in an undergraduate systematics course. Sci Ed. 2011;95(5):794823. https://doi.org/10.1002/sce.20436.

Hochpöchler U, Schnotz W, Rasch T, Ullrich M, Horz H, McElvany N, Baumert J. Dynamics of mental model construction from text and graphics. Eur J Psychol Educ. 2013;28(4):1105-26. https://doi.org/10.1007/s1021 2-012-0156-z.

Hokayem H, BouJaoude S. College students' perceptions of the theory of evolution. J Res Sci Teach. 2008;45(4):395-419. https://doi.org/10.1002/ tea.20233.

Horwitz P. Evolution is a model, why not teach it that way? In: Treagust DF, Tsui C-Y, editors. Multiple representations in biological education. Dordrecht: Springer; 2013. p. 129-45.

Kim J, Hahn J, Hahn H. How do we understand a system with (So) many diagrams? Cognitive integration processes in diagrammatic reasoning. Inform Syst Res. 2000;11(3):284-303. https://doi.org/10.1287/ isre.11.3.284.12206

Kozma R, Russell J. Students becoming chemists: developing representational competence. In: Gilbert JK, editor. Visualization in science education. Dordrecht: Springer; 2007. p. 121-46.

Kummer TA, Whipple CJ, Jensen JL. Prevalence and persistence of misconceptions in tree thinking. J Microbiol Biol Educ. 2016;17(3):389-98. https:// doi.org/10.1128/jmbe.v17i3.1156.

Lee VR. Adaptations and continuities in the use and design of visual representations in US middle school science textbooks. Int J Sci Educ 2010;32(8):1099-126. https://doi.org/10.1080/09500690903253916.

Mead LS, Scott EC. Problem concepts in evolution part I: purpose and design. Evol Educ Outreach. 2010a;3(1):78-81. https://doi.org/10.1007/s1205 2-010-0210-8.

Mead LS, Scott EC. Problem concepts in evolution part II: cause and chance. Evol Educ Outreach. 2010b;3(2):261-4. https://doi.org/10.1007/s1205 2-010-0231-3.

Meir E, Perry J, Herron JC, Kingsolver J. College students' misconceptions about evolutionary trees. Am Biol Teach. 2007;69(7):e71-6. https://doi org/10.1662/0002-7685(2007)69[71:CSMAET]2.0.CO;2.

Meisel RP. Teaching tree-thinking to undergraduate biology students. Evolution. 2010;3(4):621-8. https://doi.org/10.1007/s12052-010-0254-9.

Nehm RH, Kampourakis K. History and philosophy of science and the teaching of macroevolution. In: Matthews MR, editor. International handbook of research in history, philosophy and science teaching. Dordrecht: Springer; 2014. p. 401-21. https://doi.org/10.1007/978-94-007-7654-8_14.

Novick LR, Catley KM. Reasoning about evolution's grand patterns: college students' understanding of the tree of life. Am Educ Res J. 2013;50(1):138-77. https://doi.org/10.3102/0002831212448209.

Novick LR, Catley KM. Fostering 21st-century evolutionary reasoning: teaching tree thinking to introductory biology students. CBE Life Sci Educ. 2016. https://doi.org/10.1187/cbe.15-06-0127.

Novick LR, Catley KM, Funk D. Characters are key: the effect of synapomorphies on cladogram comprehension. Evol Educ Outreach. 2010;3(4):539-47. https://doi.org/10.1007/s12052-010-0243-z.

O'Hara RJ. Population thinking and tree thinking in systematics. Zool Scripta. 1997;26(4):323-9. https://doi.org/10.1111/j.1463-6409.1997.tb00422.x.

Omland KE, Cook LG, Crisp MD. Tree thinking for all biology: the problem with reading phylogenies as ladders of progress. BioEssays. 2008;30(9):854-67. https://doi.org/10.1002/bies.20794.

Ou CY, Ciesielski CA, Myers G, Bandea CI, Luo CC, Korber BT, et al. Molecular epidemiology of HIV transmission in a dental practice. Science 1992:256(5060):1165-71.

Purchase HC. Twelve years of diagrams research. J Vis Lang Comput. 2014:25(2):57-75. https://doi.org/10.1016/j.jvlc.2013.11.004

Roth WM, Pozzer-Ardenghi L. Pictures in biology education. In: Treagust DF, Tsui C-Y, editors. Multiple representations in biological education. Dordrecht: Springer; 2013. p. 39-53. https://doi. org/10.1007/978-94-007-4192-8_3.

Sandvik $\mathrm{H}$. Tree thinking cannot taken for granted: challenges for teaching phylogenetics. Theor Biosci. 2008;127(1):45-51. https://doi.org/10.1007/ s12064-008-0022-3. 
Searls DB. Pharmacophylogenomics: genes, evolution and drug targets. Nat Rev Drug Discov. 2003;2(8):613-23. https://doi.org/10.1038/nrd1152.

Shah P, Freedman EG, Vekiri I. The comprehension of quantitative information in graphical displays. In: Miyake A, Shah P, editors. The Cambridge handbook of visuospatial thinking. Cambridge: Cambridge University Press; 2005. p. 426-76.

Thanukos A. A name by any other tree. Evol Educ Outreach. 2009;2(2):303-9. https://doi.org/10.1007/s12052-009-0122-7.

Vosniadou S, Ioannides C, Dimitrakopoulou A, Papademetriou E. Designing learning environments to promote conceptual change in science. Eur Res Int. 2001;11(4-5):381-419. https://doi.org/10.1016/S0959-4752(00)00038 $-4$.

Wiley J, Sarmento D, Griffin TD, Hinze SR. Biology textbook graphics and their impact on expectations of understanding. Discourse Process. 2017;12:116. https://doi.org/10.1080/0163853X.2017.1319655.
Yates TB, Marek EA. Teachers teaching misconceptions: a study of factors contributing to high school biology students' acquisition of biological evolution-related misconceptions. Evol Educ Outreach. 2014;7(1):520. https://doi.org/10.1186/s12052-014-0007-2.

Yates TB, Marek EA. A study identifying biological evolution-related misconceptions held by prebiology high school students. CE. 2015;06(08):81134. https://doi.org/10.4236/ce.2015.68085.

Yates TL, Mills JN, Parmenter CA, Ksiazek TG, Parmenter RR, Vande Castle JR, et al. The ecology and evolutionary history of an emergent disease: hantavirus pulmonary syndrome. Bioscience. 2002;52(11):989. https://doi. org/10.1641/0006-3568(2002)052[0989:TEAEHO]2.0.CO;2.
Ready to submit your research? Choose BMC and benefit from:

- fast, convenient online submission

- thorough peer review by experienced researchers in your field

- rapid publication on acceptance

- support for research data, including large and complex data types

- gold Open Access which fosters wider collaboration and increased citations

- maximum visibility for your research: over $100 \mathrm{M}$ website views per year

At BMC, research is always in progress.

Learn more biomedcentral.com/submissions 